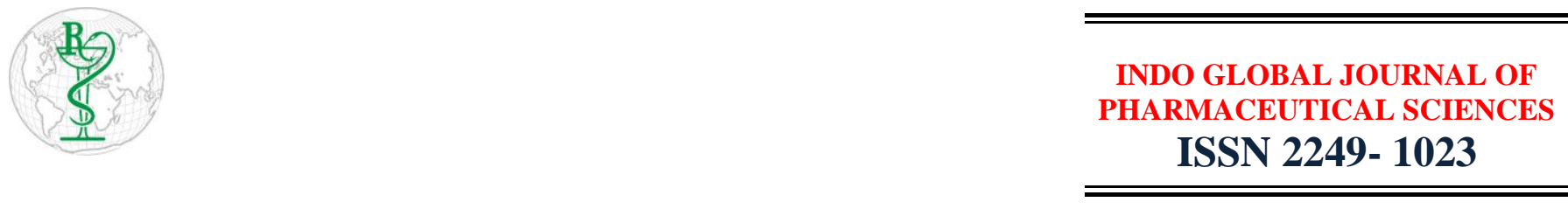

\title{
Treatment of Neuropathic Pain: A Synergy of NSAIDs \& Antidepressant
}

\author{
Shubham Kumar*, Bhuban Subedi, Srishti Choudhury, Shubham Sharma, Indu Melkani, Bimlesh \\ Kumar
}

School of Pharmaceutical Sciences, Lovely Professional University, Phagwara, Punjab, India. India

Address for Correspondence: Shubham Kumar, bimlesh.12474@lpu.co.in, shubu380@gmail.com

Received:
01.03.2019
Accepted:

25.03.2019

Keywords

Neuropathic pain; NSAIDS; Antidepressants; COX; Serotonin; Norepinephrine
ABSTRACT: Background: Neuropathic pain (NP) is an abnormality affecting somatosensory nerves system. It is one of the global challenges that affect $6.9-10 \%$ of the world population. Several analgesics, antidepressants and anticonvulsant drugs are recommended most of the time by physicians but they have several side effects as well as withdrawal responses. Hence there is the requirement of selection of drugs that can provide synergism at its lower doses in NP condition. Methods: Effects of NSAIDS and antidepressants were obtained from papers and abstracts using different electronic databases that include PubMed (www.ncbi.nlm.nih.gov./entrez/query.fcgi), ScienceDirect $\quad$ (www.sciencedirect.com), Scirus (www.scirus.com/srsapp), ISI Web of Knowledge (http://www.isiwebofknowledge.com), Google Scholar (http://scholar.google.com) and CENTRAL (Cochrane Central Register of Controlled Trials). Results: NSAIDs acts by inhibition of cyclooxygenase (COX) enzyme and antidepressants are also widely used to treat chronic pain conditions which includes both inflammatory and NP. To overcome the side effects and toxicity of NSAIDSs, various strategies have been postulated, which includes their administration at low doses, for short span and most important one is to provide them in combination with different pain modulators. NSAIDs and antidepressant act by multi pain pathway, it can provide more effect, less adverse effect, \& reduce pain if given in combination. Conclusion: NSAIDs and Antidepressants have potential to inhibit COX and increases the availability of the monoamines with reduction of prostaglandin synthesis. So, the current presentation will focus on to emphasize the comparative report of the combinations of NSAIDS and antidepressants in terms of their efficacy and safety for treatment of NP. (C) 2019 iGlobal Research and Publishing Foundation. All rights reserved.

Cite this article as: Kumar, S.; Subedi, B.; Choudhary, S.; Sharma, S.; Melkani, I.; Kumar, B. Treatment of neuropathic pain: a synergy of NSAIDs \& antidepressant. Indo Global J. Pharm. Sci., 2019; 9(2Suppl.): 103. DOI: http://doi.org/10.35652/IGJPS.2019.92S01 .

Indo Global Journal of Pharmaceutical Sciences( ISSN 2249 1023; CODEN- IGJPAI; NLM ID: 101610675) indexed and abstracted in CrossRef (DOI Enabling), UGC CARE Journal List, EMBASE(Elsevier), National Library of Medicine (NLM) Catalog, ResearchGate, Publons, CAS (ACS), Index Copernicus, Google Scholar and many more. For further details, visit http://iglobaljournal.com

This is a special issue as an outcome of 'RAPSCON-2019' sponsored by APTI and organized by Sri Sai College of Pharmacy, Manawala, Amritsar, Punjab, India. Relaxation offered in journal format. 